\title{
Readjusting Our Priorities
}

\section{Helping Homeless Youth Quit Smoking}

William G. Shadel, PhD, ${ }^{1}$ Joan S. Tucker, $\mathrm{PhD},{ }^{2}$ Daniela Golinelli, $\mathrm{PhD}^{2}$

From the ${ }^{1}$ RAND Corporation, Pittsburgh, Pennsylvania; and ${ }^{2}$ RAND Corporation, Santa Monica, California

Address correspondence to: William G. Shadel, PhD, RAND Corporation, 4570 Fifth Avenue, Suite 600, Pittsburgh PA 15213. E-mail: shadel@ rand.org. 
Best estimates indicate that approximately 1.7 million youth aged 24 years and younger in the U.S. experience homelessness each year. ${ }^{1}$ Up to $70 \%$ of unaccompanied homeless youth are smokers, according to several studies. ${ }^{2,3}$ These youth smoke more than half a pack of cigarettes per day on average, are typically daily smokers, and exhibit strong levels of nicotine dependence. ${ }^{4}$ Cigarette smoking, of course, contributes to significant short- and long-term health problems in both adults and adolescents. ${ }^{5}$ Homeless youth also tend to engage in high-risk smoking practices such as sharing cigarettes and smoking discarded butts ("sniping") that increase their risk of exposure to various infectious agents. ${ }^{6}$ Add harsh living environments, low access to medical care, generally poor nutrition, and a high prevalence of psychiatric disorders and substance abuse ${ }^{1}$ and their health likely suffers far worse than it would with cigarette smoking alone.

By any standard, this represents a significant public health crisis that should be receiving critical and careful attention from the clinical and research community. Up to this point, however, it has not: Only a handful of studies have examined the correlates of cigarette smoking or tobacco use in homeless youth ${ }^{2,3}$ and no strategies specifically targeting this vulnerable population have been developed to help them quit. Helping homeless youth quit smoking has not been a priority for either tobacco control researchers or service providers.

Historically, there may have been well-intentioned reasons for not focusing on cigarette smoking in homeless youth. This is a population with security concerns that often demand immediate attention and they suffer more from physical health issues, psychiatric illness, and substance abuse compared to non-homeless peers. ${ }^{1}$ As such, within the hierarchy of needs facing 
individuals who are homeless, the field of tobacco control may have assumed that homeless youth are not motivated to quit smoking and, moreover, that service providers working with this population are uninterested in providing smoking-cessation services.

Results from an ongoing program of research, addressing smoking among homeless youth in Los Angeles, clearly demonstrate that such concerns are misplaced. This research had two parts. First, nearly 300 unaccompanied homeless youth smokers were randomly sampled from street sites, where homeless youth congregate in Los Angeles County, and they completed a survey on their smoking-related behaviors and cognitions. Second, data were collected from a series of semi-structured telephone interviews with service providers from 23 shelters and drop-in centers serving homeless youth in Los Angeles County about their current smoking cessation programming, interest in providing smoking cessation services to their clients, potential barriers to providing this service, and ways to overcome these barriers. The overarching goals of this commentary, then, are to briefly review this program of research in order to provide a framework for conducting research with homeless youth smokers and a roadmap for helping them quit smoking.

Homeless youth smokers reported an average of nearly ten past-year quit attempts, mostly on their own without the benefit of counseling or medication. ${ }^{4}$ Among those who used any method to help them quit, the most common methods used were nicotine gum and patches; comparatively few used bupropion, varenicline, or sought professional counseling. ${ }^{4}$ Nearly half were motivated to quit smoking in the next 30 days, and the majority expressed interest in one or 
more formal cessation treatment options (e.g., group, individual, or telephone counseling; nicotine replacement).

Moreover, there is widespread interest within the shelters and drop-in centers serving homeless youth to provide treatments that can help their clients quit smoking. ${ }^{7}$ In fact, a majority of these agencies screen clients for their smoking status at some point during provision of services, although youth who screen positive for smoking are rarely given referrals and almost never provided with cessation treatment onsite. Indeed, significant challenges prevent implementation of formal cessation services in homeless shelters and drop-in centers (despite a keen interest in doing so), the most prominent of which is limited funding and staffing.

Providing smoking cessation treatment in the community service setting is not entirely out of the question, though. Service providers reported being most comfortable with adopting brief smoking cessation interventions - those that require fewer resources and are less expensive to implement. ${ }^{7}$ Fortunately, brief counseling treatments - those that take less than 15 minutes to deliver - have been shown to be effective at promoting cessation success among adults. ${ }^{5}$ The content of brief treatments is typically framed by the 5A's: Ask about smoking; Advise the individual to quit; Assess whether the individual wants to quit smoking; Assist the individual with quitting (this may include provision of medication and brief coping skills training); and Arrange for a follow-up with the individual (i.e., to check on their efforts at quitting or with medication compliance and side effects). The addition of nicotine replacement, for example nicotine patches or lozenges, and non-nicotine medications (e.g., bupropion) significantly increases quit rates over provision of brief counseling alone. ${ }^{5}$ 
Further, service providers had clear knowledge of the value and importance of offering moreintensive smoking cessation treatments. ${ }^{7}$ Indeed, smoking cessation programs that include multiple sessions and longer session times promote increased chances of cessation success over and above brief treatments. The content of more intensive treatment typically includes moreadvanced behavioral change techniques including self-monitoring and stimulus control training, relapse prevention training, and stress or mood management. ${ }^{5}$ More-intensive programs may be particularly important to implement with more complex populations of smokers ${ }^{8}$ - those that exhibit multiple comorbidities and psychiatric concerns such as with the homeless youth population. ${ }^{1}$ More generally, smoking cessation treatments can be effectively and safely provided to complex populations of smokers without fear of jeopardizing their sobriety of psychiatric stability, although these other conditions should be monitored in order to ensure their psychiatric or substance use status does not worsen. ${ }^{5}$ As such, if service agencies had sufficient financial and personnel resources (i.e., staff with adequate training and time to deliver interventions) they would likely be highly enthusiastic about implementing more comprehensive tobacco control efforts and cessation programs. ${ }^{7}$

In order to strengthen smoking cessation services for this population, there is a critical need for significantly more research that addresses not only the basic science of smoking and tobacco use but also develops and tests treatments. At the very least, future research should: develop a better understanding of factors that control and maintain smoking behavior and smoking cessation (e.g., the role of peers; family history; sale prices and tax structures, and the effect of pro-tobacco media and advertising); develop and evaluate smoking cessation interventions that are 
specifically targeted to the needs of this population including the types of offered behavioral counseling services, content of counseling sessions, lengths and intensities of counseling, different medication options, and treatment modalities (e.g., use of technology may be one important option to consider with this population); and understand the extent of use of alternative tobacco products (e.g., snus, e-cigarettes) by homeless youth. ${ }^{9}$ In fact, by making tobacco use and cessation in homeless youth a much greater research priority, the tobacco research community could improve the chances that shelters, drop-in centers, and other service organizations would develop and maintain sustainable treatments in those settings that would remain once the research is complete.

But what can be done to meet the needs of homeless youth smokers now? This is a topic area and population that—because of years of neglect from the research community—demands expeditious attention. Unfortunately, the evidence base for smoking cessation treatment among adolescents and young adults more broadly is not particularly robust. ${ }^{5}$ At first glance, then, it is challenging to envision what a cessation program targeted to this youthful population would look like. $^{\text {a }}$

One potential option is to implement smoking cessation treatments known to be effective with adult smokers. Homeless youth look a lot less like housed adolescent or young adult smokers, whose smoking tends to be more erratic and who are less nicotine dependent; they look a lot more like established adult smokers with consistent levels of daily smoking and high levels of nicotine dependence. Based on results reported above from our research with homeless youth smokers, we offer the following recommendations for community-based service providers 
working with homeless youth smokers in particular. These recommendations are also informed by general practice guidelines for treating tobacco use and dependence ${ }^{4}$ and more generally by the results on an expert panel on addressing tobacco use in homeless adult populations ${ }^{10}$ :

1. Identify one to two staff members at the site to oversee cessation programming. These individuals would not necessarily be dedicated "full time" to overseeing this programming (which may be resource prohibitive), but rather would have a portion of their time devoted to it (e.g., a program or executive director). ${ }^{7}$

2. Train all staff in delivering 3- and 15-minute smoking cessation counseling (e.g., the 5A's), based on best practices and provide staff with continuing education on smoking cessation. No cost training courses for health professionals are available online (e.g., rxforchange.ucsf.edu/); importantly, for a homeless population, these resources include modules for addressing smoking cessation with clients that have comorbid psychiatric conditions.

3. Routinely ask clients about their tobacco use and their use of alternative tobacco products as part of the intake process and at subsequent visits, recording it in a way that is accessible to all staff. Most agencies in our studies already had such a screening system in place.

4. Provide all smoking clients with at least 3-minute cessation counseling and information on how to get free or low-cost pharmacotherapy (e.g., nicotine patch or possibly bupropion); provide up to 15-minutes of one-on-one counseling as time permits.

5. Maintain an environment conducive to quitting. No cost resources are available to assist healthcare institutions with implementing a smoke free environment (smokingcessationleadership.ucsf.edu/sites/smokingcessationleadership.ucsf.edu/files/Download s/Toolkits/dtf_2013 toolkit.pdf). Some of these environmental changes could include: creating 
an entirely smoke-free facility, including outdoor smoke-free zones; having developmentally tailored reading materials on smoking cessation easily available to clients; and providing staff that are tobacco dependent assistance to quit.

6. Our work has taught us that more-intensive smoking cessation programs that include multiple sessions and full-time dedicated staff may be challenging for many service institutions owing to lack of funding and resources. However, this work has also informed us that some youth prefer more extended group-based treatment that they can attend with their friends; our work also informed us that agencies would implement a more extended treatment if the resources were available. As such, if this desire exists in the context of limited resources, service providers might consider partnering with an outside vendor, physician practice, or academic institution to leverage their resources to provide a more intensive treatment option. For example, one agency that participated in our research reported partnering with a local pharmacy for provision of professional counseling and pharmacologic support (e.g., provision of free nicotine replacement). Alternatively, following provision of brief advice to quit, staff service providers could help connect their clients with national quit lines which provide multisession counseling and sometimes free nicotine replacement (national quit line, 1-877-448-7848; local state quitline, 1800-784-8669).

7. In the event that sufficient resources can be assembled to support more-intensive programs, we recommend an onsite group-based smoking cessation program that also provides clients with nicotine replacement. Several no- to low-cost provider-centered resources and treatment manuals exist for both training (www.umassmed.edu/tobacco/training/basicskills_online/) and provision of these more-intensive services. $^{5,8}$ 
Cigarette smoking and tobacco use in homeless adults have gained increasing attention from researchers in recent years, ${ }^{11}$ but homeless youth smokers have not generated a similar level of interest. There is desire for smoking cessation services among the youth themselves and a strong willingness to help among service providers. Homeless youth have been underserved for far too long by the tobacco control community. The field must reshape its priorities so that smoking cessation among homeless youth becomes as important to it as it is to them.

${ }^{a}$ Implementing smoking prevention programs in service homeless contexts or in contexts that serve some youth prior to their becoming homeless (e.g., foster care system) may also be viable tobacco control options for this underserved population. 


\section{Acknowledgments}

This research was supported by funds from the California Tobacco-Related Disease Research

Grants Program Office of the University of California, Grant Number 21RT-0118.

WGS wrote the initial draft of this paper, and JST and DG made editorial and substantive/content contributions to the draft. WGS finalized the paper and submitted it to the journal.

No financial disclosures were reported by the authors of this paper. 


\section{References}

1. Toro PA, Dworsky A, Fowler PJ. Homeless youth in the United States: Recent research findings and intervention approaches, 2007. http://aspe.hhs.gov/hsp/homelessness/symposium07/toro/ Accessed February 25, 2015.

2. Wenzel SL, Tucker JS, Golinelli D, Green HD, Zhou A. Personal network correlates of alcohol, cigarette, and marijuana use among homeless youth. Drug Alcohol Depend. 2010;112:140-149. http://dx.doi.org/10.1016/j.drugalcdep.2010.06.004.

3. Baer JS, Ginzler JA, Peterson PL. DSM-IV alcohol and substance abuse and dependence in homeless youth. J Stud Alcohol. 2003;64:5-14. http://dx.doi.org/10.15288/jsa.2003.64.5.

4. Tucker JS, Shadel WG, Golinelli D, Ewing B, Mullins L. Motivation to quit and interest in cessation treatment among homeless youth smokers. Nicotine Tob Res. In press.

5. Fiore MC, Jaén CR, Baker TB, et al. Treating tobacco use and dependence: 2008 update. Clinical Practice Guideline. 2008. Rockville: U.S. DHHS.

6. Tucker JS, Shadel WG, Golinelli D, Mullins L, Ewing B. Sniping and other high-risk smoking practices among homeless youth. Drug Alcohol Depend. In press.

7. Shadel WG, Tucker JS, Mullins L, Staplefoote L. Providing smoking cessation programs to homeless youth: The perspective of service providers. J Subst Abuse Treat. 2014;47:251-257. http://dx.doi.org/10.1016/j.jsat.2014.05.009.

8. Abrams DB, Niaura R. Planning evidence-based treatment for nicotine dependence. In Abrams DB, Niaura R, Brown R, Emmons K, Goldstein MG, Monti PM, eds. The tobacco dependence treatment handbook. New York: Guilford Press, 2003:1-26. 
9. Tucker JS, Shadel WG, Golinelli D, Ewing B. Alternative tobacco product use and smoking cessation among homeless youth in Los Angeles County. Nicotine Tob Res. 2014;16:1522-1526. http://dx.doi.org/10.1093/ntr/ntu133.

10. Porter J, Houston L, Anderson RH, Maryman K. Addressing tobacco use in homeless populations: Recommendations of an expert panel. Health Promot Pract. 2011;12:144S151S. http://dx.doi.org/10.1177/1524839911414412.

11. Okuyemi K, Goldade K, Whembolua GL, et al. Smoking characteristics and comorbidities in the power to quit randomized clinical trial for homeless smokers. NicTob Res. 2013;15:22-28. http://dx.doi.org/10.1093/ntr/nts030. 